Proceedings of XIX International Scientific Conference "New Technologies and Achievements in Metallurgy, Material Engineering, Production Engineering and Physics", Częstochowa, Poland, June 7-8, 2018

\title{
Magnetic Characteristic of Composites Based on Nd-M-B/Polymeric Biomaterial in the Aspect of Prosthetic Applications
}

\author{
G. Pawlowska ${ }^{a, *}$, D. Klimecka-TataR ${ }^{b}, \mathrm{~K}_{\text {. Radomska }}^{a}$ And P. GęBara ${ }^{c}$ \\ ${ }^{a}$ Częstochowa University of Technology, Faculty of Production Engineering and Materials Technology, \\ Department of Chemistry, al. Armii Krajowej 19, 42-201 Częstochowa, Poland \\ ${ }^{b}$ Department of Production Engineering and Safety, Faculty of Management, \\ Częstochowa University of Technology, Częstochowa, Poland \\ ${ }^{c}$ Częstochowa University of Technology, Faculty of Production Engineering and Materials Technology, \\ Institute of Physics, Częstochowa, Poland
}

\begin{abstract}
In the paper, the novel magnetic composite based on $\mathrm{Nd}-\mathrm{M}-\mathrm{B} /$ (polymeric biomaterial) has been characterized. The composite material is dedicated to applications in magnetic retention systems, therefore typically used binders (e.g. epoxy resin) have been replaced with an acrylate. The characteristics of the magnetic properties have been presented. It has been proved that the replacement of toxic epoxy resin by polymeric biomaterial (based on PMMA) give the ability to use magnetic composite in the finished prosthetic brackets (prosthesis connector).
\end{abstract}

DOI: 10.12693/APhysPolA.135.219

PACS/topics: magnetic composite, NdFeB magnets, bonded magnets, magnetic properties

\section{Introduction}

The magnetic materials $\mathrm{RE}-\mathrm{M}-\mathrm{B}$ (where $\mathrm{RE}=$ rare earth element, $\mathrm{M}=$ transition metal) have a number of indisputable advantages, which makes that for constructors a very promising material, and the range of their applications is constantly growing. These materials, among magnetic materials are the best in terms of $B H_{\text {max }}$ value, their remanence is very high, and the volume of material needed to produce a specific magnetic field strength is much smaller than other materials $[1,2]$. The possibility of using magnets depends not only on the magnetic properties, but also on their mechanical, thermal, and chemical resistance to the destructive effects of the environment in which they will work [3]. Therefore, they are required to meet many utility criteria and not only good magnetic properties. Due to the variety of factors affecting the durability of magnetic structures, solid magnets RE-M-B are the most desirable form of hard magnetic materials. The addition of binder and/or porosity is the reason for the decrease in the magnetic properties of the material, especially its coercivity and remanence $[4,5]$. Great popularity also acquire magnetic composites, where components are powder based on alloy with magnetic properties (e.g. Nd-Fe-B) and the thermo- or chemically-setting binding materials (e.g. epoxy resin) [6, 7]. Magnetic composites gain their advantage over sintered materials due to the easier production technology (not requiring

\footnotetext{
* corresponding author
}

specialist technical equipment) $[8,9]$. The essential part of the technological process consists of simple plastics processing operations and can be dealt by small enterprises. Bonded magnets are obtained from high-coercive powders that can be achieved in the process of rapid cooling from the molten state (melt spinning), hydrogenation disproportional desorption recombination (HDDR) method, the spraying of the liquid phase (spray atomizing), and by grinding elements or alloys [1, 10, 11].

A serious difficulty in the process of obtaining RE-M-B powders is their surface oxidation. Powders show a much higher degree of oxidation than their solid counterparts. The easier oxidation of powders results from the larger, and developed surface that can react with oxygen. The percentage of oxide phases in a powder composition increases with the fragmentation of the powder particles, especially when the process takes place at elevated temperature. It has been found that the satisfactory effects of minimizing the effect of the oxide phases presence can be obtained by pre-etching of powders surface. Further limitation of corrosion processes can be obtained in the process of magnetic powder encapsulation $\mathrm{RE}-\mathrm{M}-\mathrm{B}$ with $\mathrm{Ni}-\mathrm{P}$ coatings, phosphate coatings, $\mathrm{Cu}$ coatings, silicate coatings, or surface modification [12-15]. In addition, to ensure adequate durability of the composite material, the material used as a binder should be as low as possible permeable to the environment - poorly absorbable, because bonding material can play role of an additional protective coating (biencapsulation).

The binder content, its ability to consolid the powder, as well as biotorelability properties are particularly important for the potential use of these composites 
in restorative medicine. Magnetic coupling based on $\mathrm{Nd}-\mathrm{Fe}-\mathrm{B}$ composites can be used as an element of retention maintenance of overlay prostheses and face epithesis. In medical applications [16-19], there is no need to use magnets with the highest magnetic properties, therefore bonded materials with slightly worse properties than sintered are sufficient. The use of RE-M-B powder-based composites in medicine excludes the possibility of using the most popular binder, epoxy resin, due to its toxicity. This work contains magnetic characteristics of selected composites based on RE-M-B powders, consolidated with a biotolerable binder with respect to the possibility of use in reconstructive medicine.

\section{Experimental}

In this paper, the characteristics of magnetic composites based on a commercial powder with a chemical formula $\mathrm{Nd}_{12} \mathrm{Fe}_{77} \mathrm{Co}_{5} \mathrm{~B}_{6}$ and irregular particle shape were presented (fraction $50 \div 150 \mu \mathrm{m}$ ). In order to remove oxides from the powder surface, according to the procedure presented in the paper [14], the powders have been etched in a $5 \%$ aqueous solution of oxalic acid, rinsed with acetone and distilled water and dried under protective atmosphere. The process of composites consolidation for research has been carried out in accordance with the scheme shown in Fig. 1. This paper presents the results of magnetic measurements for three representative samples, in which the binder content was 3, 10, and 20 mass\%.

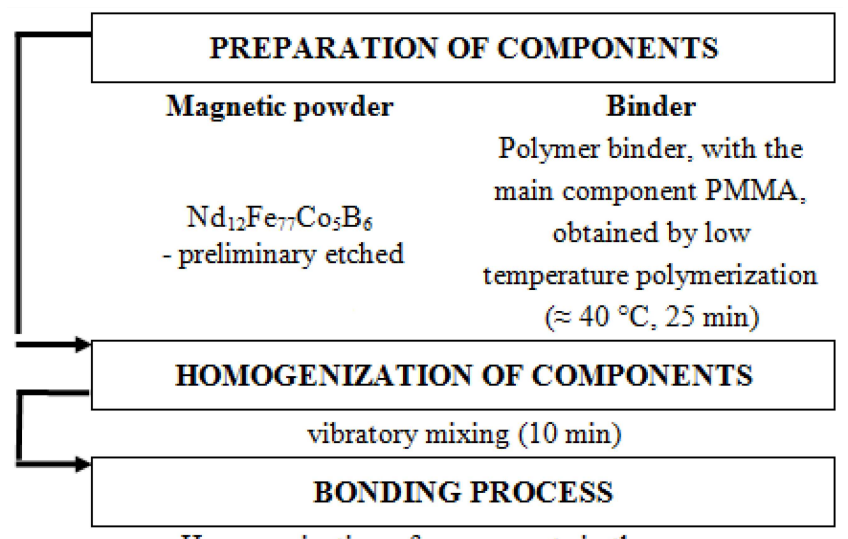

Homogenization of components in the process of polymerization in a water bath with simultaneous molding in a die under the pressure of $7 \mathrm{MPa}$ (single-side and single-axial pressing)

Fig. 1. Diagram of the a magnetic composite RE-M$\mathrm{B} /$ polymeric biomaterial preparation process.

For evaluation of the magnetic properties of composite the vibrating sample magnetometer (LakeShore VSM 7307) has been used. The dependence of the sample magnetization in the range $-1500 \div+1500 \mathrm{kA} / \mathrm{m}$ was determined and the magnetic hysteresis loops were recorded. Measurements of the external magnetic field were carried out using a Hall probe. Magnetic research was also carried out on a ready-to-use prosthetic magnetic hitch.
Cylindrical composite samples were magnetized and subjected to various loads until the magnetic joint was broken. In the study, the functional efficiency of magnetic joints was evaluated - at which value of force the joints would open when the displacement was $0.1 \mathrm{~mm}$.

\section{Results and discussion}

On the basis of the conducted research, it has been observed that the increase of the binder content in the RE-M-B/polymeric biomaterial composite has an effect on the magnetic properties. Furthermore, the tested composite material belongs to the group of ferromagnetic materials exhibiting the hysteresis phenomenon. In Fig. 2 the hysteresis loops characteristic for hard magnetic materials are presented. Based on the measurements the main parameters characterizing the magnetic materials have been determined and the values of these parameters obtained for the RE-M-B/polymeric biomaterial composite with different binder content are shown in Table I.
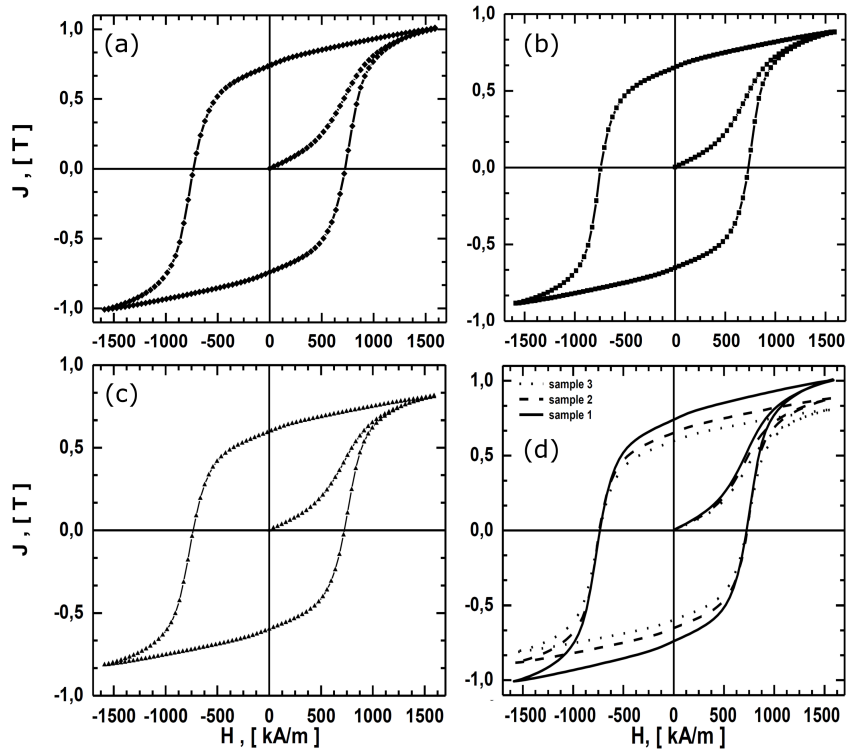

Fig. 2. Magnetic hysteresis loops of the RE-MB/polymeric biomaterial composite: (a) sample 1 (3 wt\% polymeric biomaterial), (b) sample 2 (10 wt\% polymeric biomaterial), (c) sample 3 (20 wt\% polymeric biomaterial), (d) comparison.

TABLE I

Selected magnetic parameters of the $\mathrm{RE}-\mathrm{M}-\mathrm{B} /$ polymeric biomaterial composite.

\begin{tabular}{c|c|c|c|c|c}
\hline \hline \multicolumn{5}{c}{ RE-M-B/polymeric biomaterial composite } \\
\hline $\begin{array}{c}\text { Sample } \\
\text { number }\end{array}$ & $\begin{array}{c}\text { Sample designation } \\
\text { [wt\% polymeric } \\
\text { biomaterial] }\end{array}$ & \multicolumn{4}{|c}{ Magnetic parameters } \\
\cline { 3 - 6 } & $J_{r}$ & $H_{c}$ & $J_{s}$ & $B H_{\max }$ \\
{$[\mathrm{kA} / \mathrm{m}]$} & {$[\mathrm{T}]$} & {$\left[\mathrm{kJ} / \mathrm{m}^{3}\right]$} \\
\hline 1 & 3 & 0.74 & 728 & 1.00 & 87 \\
2 & 10 & 0.65 & 740 & 0.88 & 71 \\
3 & 20 & 0.58 & 727 & 0.80 & 62
\end{tabular}


The magnetic properties of the RE-M-B/polymeric biomaterial composite are mainly characterized by the maximum energy product $B H_{\max }$, which is dependent on the coercive field $H_{c}$, polarization remanence $J_{r}$ and the shape of the hysteresis loop. For this type of composites it is characteristic that increase of the binder content contributes to the reduction of polarization remanence $J_{r}$. According to the data presented in Table I, remanence value $J_{r}$ is the highest for sample 1 in which the content of the non-magnetic binder is the smallest $-J_{r} \approx 0.74 \mathrm{~T}$. With the increase of the non-magnetic binder content, the remanence value $J_{r}$ decreases, and the coercive value $H_{c}$ should initially increase (increase the magnetic insulation of the powder particles) and then gradually decrease. In the case of the tested RE-M-B/polymeric biomaterial composite (samples 1-3), this tendency is maintained. The value of remanence decreases as the proportion of binder in the material increases, and the dependence of coercive field $H_{c}$ on the binder content shows the local extremum (Fig. 3).


Fig. 3. Variability of magnetic properties depending on the content of binder in the RE-M-B/polymeric biomaterial composite - for materials containing 3, 10, and $20 \mathrm{wt} \%$ of polymeric biomaterial.

As can be seen, for low binder content the material has a relatively high coercivity value, which confirms good insulation of the magnetic powder particles of the composite. The decrease in the coercive field $H_{c}$ for sample 3 (20 wt\% binder) is probably the result of too large distances between the magnetic particles preventing them from interacting with each other.

The new RE-M-B/polymeric biomaterial composite has been designed as a potential element of retention maintenance. It is supposed to be subjected to vertical forces and charged the weight of moving parts of e.g. ear epithesis, prosthesis, prosthetic crown. Therefore, it was necessary to study the maximum load value of the composite for maintaining the appropriate retention system. A retention system composed of a $\mathrm{RE}-\mathrm{M}-\mathrm{B} /$ polymeric biomaterial composite and a ferromagnetic material were magnetized in a magnetic field and subjected to load evaluation in two variants - magnetized in direct contact and at distance of $2 \mathrm{~mm}$ (Fig. 4, Table II). The results presented in Table II and Fig. 4 indicate that a one of the composite-based joints has the ability to maintain a prosthetic structure up to $93 \mathrm{~g}$ in the case of direct connection and $48.0 \mathrm{~g}$ in the case of increasing the distance in the connector. These results are satisfactory because, for example, the total upper prosthesis or ear epithesis weigh on average 20-30 g, and to maintain them 2-4 connectors are most often used.

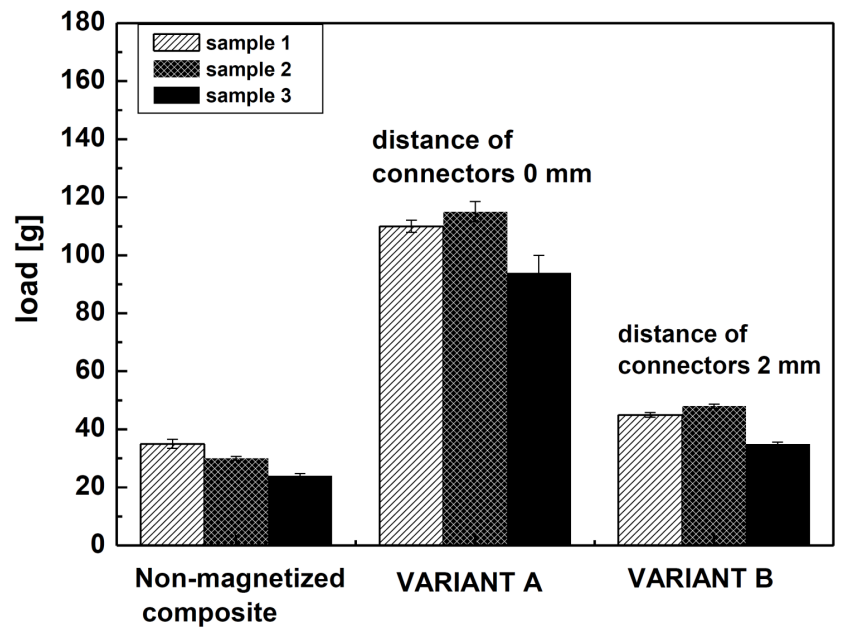

Fig. 4. Comparison of the maximum load of the RE$\mathrm{M}-\mathrm{B} /$ polymeric biomaterial composite in a connector depending on the binder content in the composite.

TABLE II

Evaluation of the maximum load of the RE-M-B/polymeric biomaterial composite in the connector. NM non-magnetized connector in direct contact, A - magnetized connector in direct contact (variant A), B - magnetized connector at a distance of $2 \mathrm{~mm}$ (variant B).

\begin{tabular}{|c|c|c|c|}
\hline \multirow{5}{*}{$\begin{array}{c}\text { Measurement } \\
\text { variant }\end{array}$} & \multicolumn{3}{|c|}{ RE-M-B/polymeric biomaterial compos } \\
\hline & $1(3 \mathrm{wt} \%$ & $2(10 \mathrm{wt} \%$ & $3(20 \mathrm{wt} \%$ \\
\hline & polymeric & polymeric & polymeric \\
\hline & biomaterial) & biomaterial) & biomaterial) \\
\hline & \multicolumn{3}{|c|}{ Maximum load values [g] } \\
\hline NM & $35 \pm 0.97$ & $30 \pm 0.69$ & $24 \pm 0.79$ \\
\hline A & $110 \pm 0.93$ & $115 \pm 3.44$ & $94 \pm 1.53$ \\
\hline $\mathrm{B}$ & $45 \pm 0.8$ & $48 \pm 0.7$ & $35 \pm 0.3$ \\
\hline
\end{tabular}

In order to determine the destabilization of the retention system, the material has been treated with a oneway axial force in such a way that it would to destabilize the retention system. Measurements have been made in the displacement range of $0.1 \mathrm{~mm}$ for all samples $1 \div 3$ (3, 10, and $20 \mathrm{wt} \%$, respectively), and the results are shown in Fig. 5. Obtained results showed that in order to open the magnetic joints with $0.1 \mathrm{~mm}$ displacement, a force of $\approx 1 \mathrm{~N}$ must be applied for samples 1 and 2 


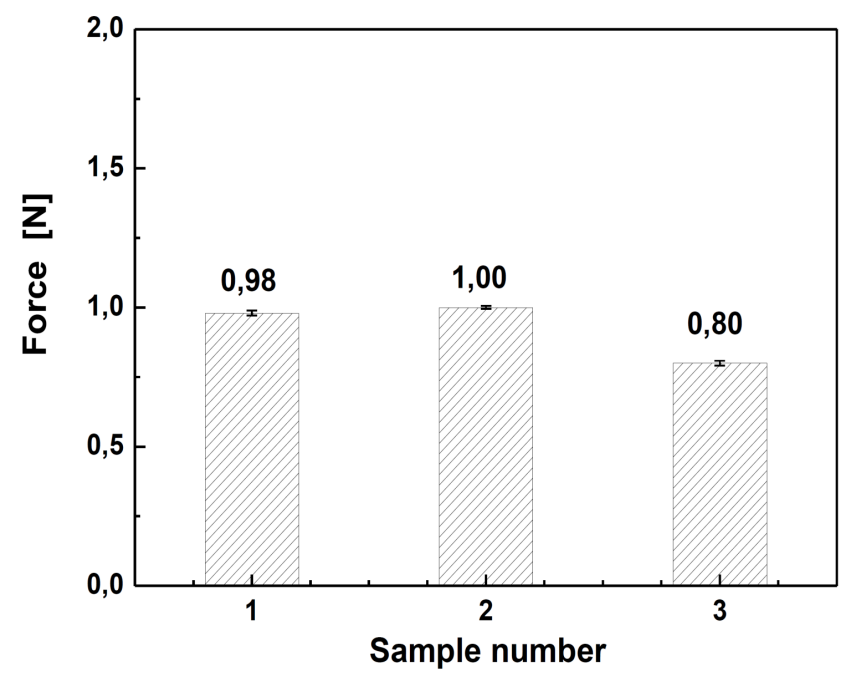

Fig. 5. The value of the force necessary to destabilize the RE-M-B/polymeric biomaterial composite in a connector system at a displacement of $0.1 \mathrm{~mm}$.

( 3 and $10 \mathrm{wt} \%$ polymeric biomaterial) whereas for sample 3 (20 wt\% polymeric biomaterial) must be applied a force of $0.8 \mathrm{~N}$, which is at the lower limit of the minimum forces to maintain the prosthesis.

\section{Conclusions}

- The value of remanence decreases as the proportion of binder in the material increases, and the dependence of coercive field $H_{c}$ on the binder content shows the local extremum.

- Single composite-based joint has the ability to maintain a prosthetic structure up to $93 \mathrm{~g}$ in the case of direct connection.

- The worst resistance to destabilization of retention system is demonstrated by the material with $20 \mathrm{wt} \%$ of polymeric biomaterial.

\section{References}

[1] M. Leonowicz, J.J. Wysłocki, in: Contemporary Magnets, WNT, Warszawa 2005 (in Polish).

[2] H. Akin, M.E. Coskun, E.G. Akin, A.K. Ozdemir, J. Prosthet. Dent. 105, 203 (2011).
[3] X.H. Zhang, W.H. Xiong, Y.F. Li, N. Song, Mater. Des. 30, 1386 (2009).

[4] T. Saito, S. Nozaki, D. Nishio-Hamane, J. Magn. Magn. Mater. 445, 49 (2018).

[5] L. Li, K. Jones, B. Sales, J.L. Pries, I.C. Nlebedim, K. Jin, H. Bei, B.K. Post, M.S. Kesler, O. Rios, V. Kunc, R. Fredette, J. Ormerod, A. Williams, T.A. Lograsso, M.P. Paranthaman, Addit. Manufact. 21, 495 (2018).

[6] D. Klimecka-Tatar, H. Bala, B. Ślusarek, K. Jagielska-Wiaderek, Arch. Metal. Mater. 54, 247 (2009).

[7] F. Zhai, A. Sun, D. Yuan, J. Wang, S. Wu, A.A. Volinsky, Z. Wang, J. Alloys Comp. 509, 687 (2011).

[8] B. Ma, A. Sun, Z. Lu, C. Cheng, C. Xu, J. Magn. Magn. Mater. 401, 802 (2016).

[9] Muljadi, P. Sardjono, Suprapedi, Energy Proced. 68, $282(2015)$.

[10] E. Vasilyeva, V. Vystavkina, J. Magn. Magn. Mater. 267, 267 (2003).

[11] D.N. Brown, Z. Chen, P. Guschl, P. Cambell, J. Magn. Magn. Mater. 303, e371 (2006).

[12] G. Pawłowska, D. Klimecka-Tatar, A. Mazik, Ochrona przed Korozja 56, 174 (2013) (in Polish).

[13] D. Klimecka-Tatar, G. Pawłowska, K. Radomska, Ochrona przed Korozja 56, 187 (2013) (in Polish).

[14] D. Klimecka-Tatar, G. Pawłowska, M. Sozańska, Arch. Metal. Mater. 60, 77 (2015).

[15] B. Ma, A. Sun, Z. Lu, C. Cheng, C. Xu, J. Magn. Magn. Mater. 416, 150 (2016).

[16] S.R. Zwetchkenbaum, W.-S. Oh, J. Prosthet. Dent. 105, 208 (2011).

[17] M. Hasegawa, Y. Umekawa, E. Nagai, T. Ishigami, J. Prosthet. Dent. 105, 266 (2011).

[18] Z. Hao, Y. Chao, Y. Meng, H. Yin, J. Prosthet. Dent. 112, 235 (2014)

[19] F. Fabiano, V. Puliafito, L. Calabrese, C. Borsellino, L.M. Bonaccorsi, A. Giordano, V. Fabiano, G. Cordasco, Physica B Condens. Matter 486, 151 (2016). 